\title{
Ion exchanges between glass-ionomer restorative material and primary teeth components-an in vivo study
}

\author{
Uri Zilberman \\ Correspondence: uri-z@smile.net.il

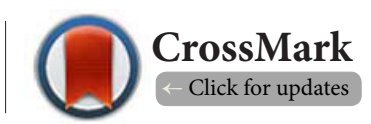

Head of the Pediatric Dental Unit, Barzilai Medical Center (Ashkelon) affiliated to Ben-Gurion University, Beer Sheva, Israel.

\begin{abstract}
Objectives: To analyze the ion exchange between conventional glass-ionomer restorative material, (Fuji IX- GC Co., Japan) and tooth components in primary molars after long periods of function in vivo.

Methods: Five deciduous mandibular molars were collected after normal exfoliation. An intact deciduous molar served as control, a second deciduous molar was restored occlusaly with Fuji IX in vitro, and 3 deciduous molars with occlusal restorations were collected after 18,24, and 48 months in vivo. The molars were sectioned bucco-lingual through the restoration and the chemical analysis was performed on enamel, dentin and restorative material along parallel lines crossing from buccal to lingual, using an energy dispersive X-ray spectrometer (EDS). The data was analyzed using SPSS program.

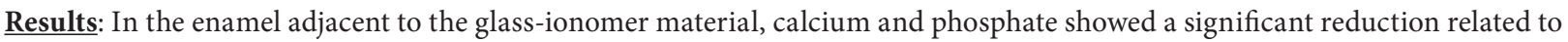
time $(\mathrm{P}<0.05)$. In both enamel and dentin strontium, silica and alumina migrated from the glass-ionomer material in significant concentrations $(\mathrm{P}<0.05)$, and fluorine showed an increase from zero in the intact deciduous molar to $1.2 \%$ after four years in vivo. In the glass-ionomer material fluorine was reduced in relation with time in vivo, while calcium concentration increased.

Conclusions: There is a constant exchange of ions between glass-ionomer restorative material and tooth components in deciduous molars. It begins as early as two weeks in vitro and is increased in vivo. Strontium, alumina and fluorine released from the glassionomer have a bactericidal effect and may affect remineralization. Calcium may enhance the glass-ionomer mineralization and transform it into enamel like material.

Clinical significance: The results showed that a continuous exchange of ions between enamel and dentin and glass-ionomer material occurs in vivo and the concentration of the ions is time related. Strontium, alumina and fluorine in enamel and dentin may cause a continuous anti bacterial and anti cariogenic effect, while calcium enhance mineralization of glass-ionomer in vivo, a factor that may increase the longevity of the restoration.
\end{abstract}

Keywords: Glass-ionomer, deciduous molars, strontium, alumina, fluoride, calcium

\section{Introduction}

The potential of remineralization of carious lesions in dentin in vitro by glass-ionomer cements $(\mathrm{GIC})$ has been long established [1], and related to the release of fluoride ions from the restorative material. Diffusion of additional ions from GIC, like calcium, strontium, and magnesium have an important effect on demineralized dentin in vivo in permanent teeth [2]. The levels of calcium, phosphate and fluoride in primary molars restored with GIC were higher than in intact teeth after one month in vivo [3]. As early as 1953, the importance of strontium in low caries prevalence was suggested [4]. Since then, several reports emphasized the effect that strontium has on dental caries levels [5-7]. The levels of strontium in enamel of premolars from patients with low DMF (Decayed, Missing, and Filled teeth) were significantly higher than the levels found in patients with high DMF [7]. The level of strontium in teeth was related to its concentration in the drinking water and affected the DMF values [8] in low fluoridated areas. Strontium was supposed to have a cariostatic effect if administered prenatal compared to post-natal, as demonstrated in rodents [9]. In carious teeth the concentration of strontium was significantly lower when compared to intact teeth [10-11]. Blood concentration of strontium, phosphate and fluorine was significantly lower in patients with high carious activity in comparison with patients with low carious activity [12]. In saliva, the concentration of strontium was higher in children with caries experience in comparison to the saliva concentration of strontium in children with sound teeth and fluorine was found to inhibit strontium dissolution from teeth during carious attack [13]. Strontium and fluorine can be found in glass-ionomer cements used for bases or restorations of primary and permanent teeth. The biocompatibility of glass-ionomer cements has been revised and the material has shown to exert some antibacterial properties related to the fluoride release with no adverse effect on pulp tissue if a bacterial layer under the restoration and pulp exposures were prevented [14]. In vitro analyses showed that there is a chemical exchange of fluorine and strontium ions between glass-ionomers restorations and 
dentin in permanent molars after 1-3 months [2], and that the pattern of penetration of these ions was consistent with a remineralization process. The ion migration of strontium and fluorine from a conventional glass-ionomer material into dentine and enamel of permanent $3^{\text {rd }}$ molars in vitro after 18 months was significant [15]. Glass-ionomer cements showed antibacterial activity in vitro [16-17].

The aim of this study was to evaluate the ion exchange between the restorative material and deciduous tooth components, enamel and dentin, and to relate the amount to time of function in vivo.

\section{Materials and methods}

A total of five mandibular deciduous molars were used for this study. The molars were collected from children attending a pediatric dental clinic, after normal exfoliation. An intact second deciduous molar was used as control. An occlusal cavity was performed in a deciduous first intact molar, restored in vitro with conventional glass-ionomer according to the manufacturer instructions (Fuji IX, GC Co, Japan) and kept in moisture condition for two weeks before analysis. A first deciduous molar with an occlusal restoration was received after 18 months in the mouth and two second deciduous molars with occlusal restorations were collected after 24 and 48 months in the mouth. All restorations were performed by the same clinician using the same conventional glass ionomer material (Fuji IX, GC Co, Japan) under rubber-dam according to manufacturer instructions. The three in vivo retrieved teeth were kept dry in a plastic tube till sectioning and chemical analysis. The molars were sectioned bucco-lingual through the restoration using a high speed diamond bur (E1), under copious amount of water and polished using sand paper disks. The mesial halves were used for SEM examinations. A Fuji 9 capsule was mixed, set to dry on a glass plate and the material examined in order to determine the composition of the restoration material.

Chemical analysis was carried out using SEM ("Quanta" made by FEI (Field Emission Instruments), Netherlands), energy dispersive $\mathrm{X}$-ray spectrometer (EDS) in a low vacuum mode in order to identify the main elements in the enamel, dentin and restoration. The analyzed surface was mounted into the SEM chamber parallel to the table. On the restorative material the composition was examined on the flat surface in the middle of the bulge. On each sectioned tooth, elements concentration was determined on two lines- a line from buccal enamel through the restoration to the lingual enamel and a parallel line from the buccal dentin through the restoration to the lingual dentin (Figure 1). On the intact tooth similar lines were analyzed. On each line 300 examination points were performed by the SEM-EDS. The molar values of the elements were calculated by the SEM-EDS and the results were expressed in percentages. The basic tooth structure consists of hydroxyapatite crystals with the formula $\mathrm{Ca}_{10}\left(\mathrm{PO}_{4}\right)_{6} \mathrm{OH}_{2}$, and so the main chemical composition of the intact tooth is primary calcium, phosphate and oxygen with traces of carbon, sodium and magnesium. The elements found in the Fuji 9 material included carbon, oxygen, fluorine, sodium, alumina, silica, strontium and phosphate. Based on this data, the elements examined on each line included calcium, phosphate, oxygen, carbon, sodium, magnesium, silica, alumina, strontium and fluorine. The composition of the enamel and dentin includes hydroxyl groups which cannot be counted and the results for oxygen are not accurate.

All data was transferred to the computer and analyzed statistically using the SSPS package. The Scheffe post-hoc analysis, part of the ANOVA, was performed to determine the differences between teeth for each component analyzed, with $a=5 \%$.

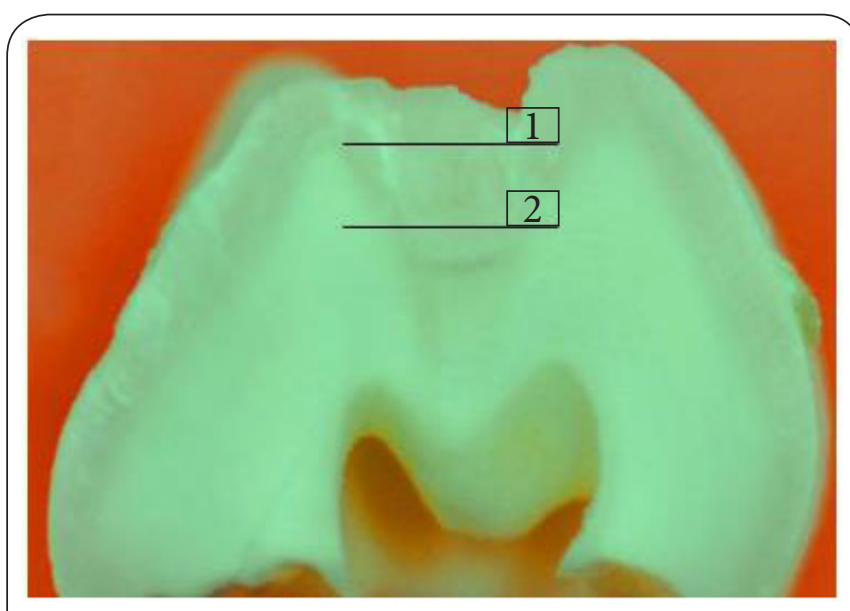

Figure 1. The lines of EDS analyses: On each line 300 points were analyzed.

1. upper line-through the buccal enamel, the glass-ionomer restoration and lingual enamel.

2. lower line-through the buccal dentin, the glass-ionomer restoration and the lingual dentin.

\section{Results}

(Table 1) shows the mineral content of enamel in the intact molar and the in vitro and in vivo restored molars. The main mineral components in the intact enamel were calcium, phosphate, oxygen, carbon, sodium and magnesium. A significant reduction of calcium (20\%) and phosphate (22\%) was observed after 4 years in vivo, while strontium, silica and alumina appeared in the enamel after restoration placement and showed a significant increase related to time. Fluorine appeared in the enamel after the glass-ionomer restoration was performed, in vitro and in vivo, and increased from $0.9 \%$ to $1.2 \%$ in vivo, related to the time the restoration functioned in the mouth. In the in vitro restored tooth the fluorine content in the enamel reached $1.2 \%$. Sodium concentration decreased when the glass-ionomer restoration was placed, while magnesium showed similar results in intact and restored teeth. Carbon content increased in the enamel and the increase was related to time in vivo. 
Uri Zilberman, Oral Biology and Dentistry 2014,

In the dentin (Table 2) the amount of calcium was similar in all molars examined, and phosphate reduction was not significant between the intact molar and molars with glassionomer restorations. Oxygen and carbon were reduced in molars with glass-ionomer restorations and related to time in vivo. Strontium, silica and alumina were transferred from the glass-ionomer restoration to the dentin and their concentrations were related to the time the glass-ionomer restorations functioned in the mouth. Fluorine in significant amount was detected in the dentin after the glass-ionomer restoration was performed and it reached $1.2 \%$ after four

Table 1. Enamel content, Mean and (SD) in \%.

\begin{tabular}{llllll}
\hline & $\begin{array}{l}\text { Intact tooth } \\
\mathbf{N = 7 9}\end{array}$ & $\begin{array}{l}\text { In vitro } \\
\mathbf{N}=\mathbf{1 1 0}\end{array}$ & $\begin{array}{l}\mathbf{1 8} \text { months } \\
\mathbf{N = 4 0}\end{array}$ & $\begin{array}{l}\mathbf{2 4} \text { months } \\
\mathbf{N = 5 9}\end{array}$ & $\begin{array}{l}\mathbf{4 8} \text { months } \\
\mathbf{N}=79\end{array}$ \\
\hline Calcium & $40.8(2.4)$ & $38.6(4.2)$ & $38.0(2.2)$ & $33.5(1.7)$ & $32.6(4.7)$ \\
Phosphate & $34.1(2.0)$ & $30.8(2.9)$ & $32.4(1.5)$ & $28.8(1.6)$ & $26.1(3.8)$ \\
Oxygen & $15.7(1.7)$ & $11.3(2.1)$ & $10.8(1.9)$ & $14.6(1.4)$ & $13.9(2.3)$ \\
Carbon & $3.7(2.1)$ & $2.4(0.9)$ & $3.8(1.3)$ & $4.8(0.9)$ & $6.3(4.7)$ \\
Fluorine & 0 & $1.2(0.4)$ & $0.9(0.3)$ & $1.1(0.8)$ & $1.2(0.5)$ \\
Strontium & 0 & $4.3(1.3)$ & $3.9(0.7)$ & $4.4(0.8)$ & $5.6(2.3)$ \\
Silica & 0 & $4.0(1.4)$ & $3.7(0.7)$ & $3.9(0.7)$ & $5.4(1.9)$ \\
Alumina & 0 & $2.8(1.9)$ & $2.0(0.5)$ & $2.7(0.5)$ & $3.7(1.6)$ \\
Sodium & $3.3(1.0)$ & $2.5(0.7)$ & $2.6(0.6)$ & $2.9(0.7)$ & $2.5(0.7)$ \\
Magnesium & $2.5(0.7)$ & $2.1(0.5)$ & $2.0(0.6)$ & $3.2(0.5)$ & $2.7(0.7)$ \\
\hline
\end{tabular}

Note: N- number of points analyzed on each component. The number differs according to the width of enamel, dentin and restoration.

Table 2. Dentin content, Mean and (SD) in \%.

\begin{tabular}{llllll}
\hline & Intact tooth & In vitro & $\mathbf{1 8}$ months & $\mathbf{2 4}$ months & 48 months \\
& $\mathbf{N}=\mathbf{2 2 0}$ & $\mathbf{N}=\mathbf{1 6 7}$ & $\mathbf{N}=\mathbf{1 1 1}$ & $\mathbf{N = 6 0}$ & $\mathbf{N = 6 2}$ \\
\hline Calcium & $36.0(2.6)$ & $35.8(2.3)$ & $33.6(3.0)$ & $34.3(5.0)$ & $35.2(3.3)$ \\
Phosphate & $31.1(2.4)$ & $29.6(1.8)$ & $29.7(1.9)$ & $27.3(4.3)$ & $28.5(2.7)$ \\
Oxygen & $18.4(1.8)$ & $12.8(1.8)$ & $12.9(2.3)$ & $11.9(2.6)$ & $13.1(1.6)$ \\
Carbon & $6.9(2.9)$ & $5.2(1.6)$ & $6.4(2.4)$ & $3.0(1.9)$ & $3.7(1.8)$ \\
Fluorine & 0 & $0.9(0.4)$ & $1.0(0.4)$ & $1.2(0.6)$ & $1.2(0.4)$ \\
Strontium & 0 & $4.0(0.7)$ & $4.1(0.8)$ & $7.0(0.8)$ & $5.2(1.7)$ \\
Silica & 0 & $3.7(0.7)$ & $3.8(0.7)$ & $4.0(0.7)$ & $5.0(1.4)$ \\
Alumina & 0 & $2.3(0.6)$ & $2.3(0.6)$ & $4.4(0.6)$ & $3.5(1.5)$ \\
Sodium & $3.7(1.1)$ & $2.4(0.6)$ & $3.3(1.5)$ & $2.5(1.1)$ & $2.3(0.6)$ \\
Magnesium & $3.9(0.7)$ & $3.3(0.6)$ & $2.9(0.7)$ & $1.9(0.9)$ & $2.2(0.6)$ \\
\hline
\end{tabular}

Note: N- number of points analyzed on each component. The number differs according to the width of enamel, dentin and restoration.

years in vivo. Sodium and magnesium decreased after glassionomer restoration was performed and related to time in vivo. (Table 3) shows the mineral content of glass-ionomer restorations performed in vitro and in vivo. Calcium con-centration increased from $2.5 \%$ in vitro to $4.2 \%$ after 48 months in vivo. Phosphate, oxygen and carbon showed similar concentrations in all molars. Fluorine concentration was reduced from $6 \%$ in vitro to $3.5 \%$ after 24 months in vivo and remained constant for the next 24 months. Strontium and silica concentration increased with time and alumina showed similar concentrations. Sodium concentration decreased in relation to time and

Table 3. Restoration content, Mean and (SD) in \%.

\begin{tabular}{lllll}
\hline & $\begin{array}{l}\text { In vitro } \\
\mathbf{N}=\mathbf{2 7 8}\end{array}$ & $\begin{array}{l}\mathbf{1 8} \text { months } \\
\mathbf{N}=\mathbf{3 1 3}\end{array}$ & $\begin{array}{l}\text { 24 months } \\
\mathbf{N = 1 4 0}\end{array}$ & $\begin{array}{l}\text { 48 months } \\
\mathbf{N}=\mathbf{3 2 7}\end{array}$ \\
\hline Calcium & $2.5(1.0)$ & $2.3(1.3)$ & $4.0(2.2)$ & $4.2(0.8)$ \\
Phosphate & $5.2(0.9)$ & $5.0(1.2)$ & $6.6(2.5)$ & $5.2(0.9)$ \\
Oxygen & $14.5(3.1)$ & $12.2(2.0)$ & $12.7(2.2)$ & $12.9(2.0)$ \\
Carbon & $3.4(2.3)$ & $2.8(1.4)$ & $2.7(3.4)$ & $2.7(1.6)$ \\
Fluorine & $6.0(1.3)$ & $6.2(1.4)$ & $3.5(0.9)$ & $3.7(0.8)$ \\
Strontium & $18.9(1.9)$ & $19.9(1.6)$ & $22.5(3.7)$ & $24.1(1.7)$ \\
Silica & $20.0(2.2)$ & $21.5(1.8)$ & $22.5(2.9)$ & $23.9(1.8)$ \\
Alumina & $22.7(2.1)$ & $23.7(2.1)$ & $19.9(3.8)$ & $21.7(2.2)$ \\
Sodium & $5.5(0.8)$ & $5.0(1.9)$ & $3.9(1.9)$ & $2.7(1.6)$ \\
Magnesium & $1.5(0.3)$ & $1.5(0.4)$ & $1.7(0.4)$ & $1.5(0.4)$ \\
\hline
\end{tabular}

Note: N- number of points analyzed on each component. The number differs according to the width of enamel, dentin and restoration.

magnesium remained constant.

(Figure 2) shows the results for calcium, fluorine and strontium on both sides of the interface between the glass ionomer material and dentin, in order to determine if the concentration of the components is related to the distance from the interface. The scattergram shows that the changes in the components content occur abruptly when the interface is crossed and the effect of distance from the interface is minimal. The values near the interface were not taken into consideration for statistical analyses.

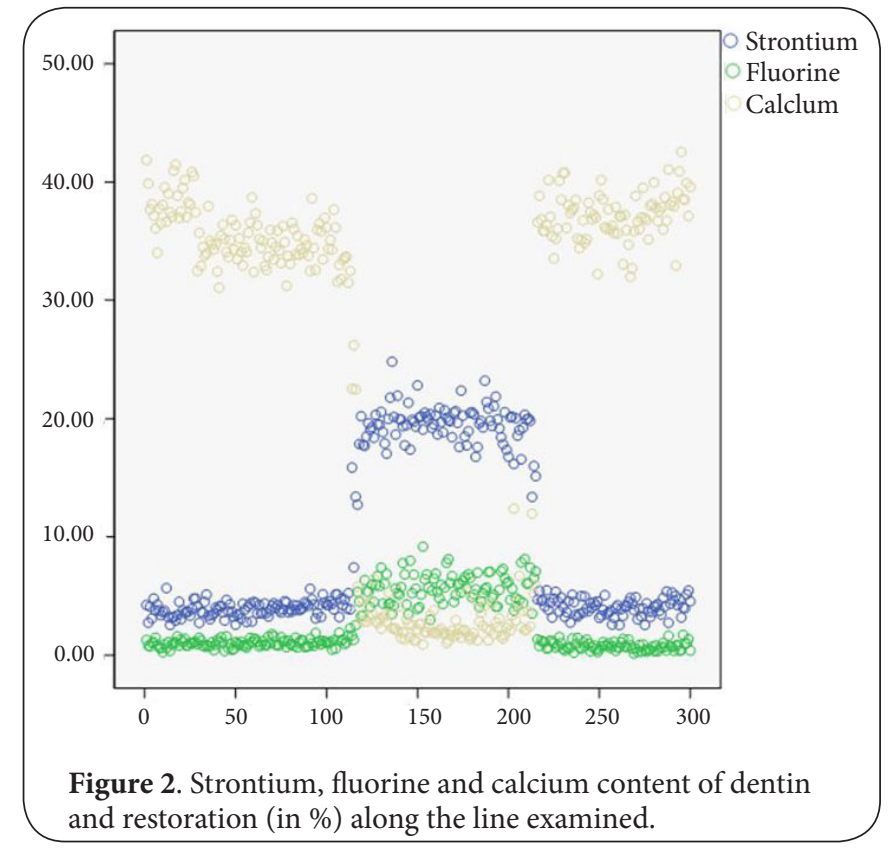


The Scheffe post-hoc analysis performed looks at differences between each two teeth for each component and is part of the ANOVA. For enamel, calcium and phosphate showed a significant decrease during time and strontium, silica and alumina showed a significant increase over time $(P<0.05)$. In dentin, strontium, silica and alumina showed a significant increase over time, and carbon content decreased $(P<0.05)$. Fluorine content in the enamel and dentin of the restored teeth showed a significant increase when compared to the intact tooth.

\section{Discussion}

The study examined the exchange of ions between glassionomer material (Fuji IX) and enamel and dentin of deciduous mandibular molars restored on the occlusal surface. One intact molar was used as control, and another molar was restored in vitro and kept in moisture condition for two weeks before analysis. Three deciduous molars were collected after 18-48 months function in the mouth. The results showed a continuous transfer of ions between glass-ionomer restorative material and the enamel and dentin. This exchange occurs as early as two weeks in vitro and increases in vivo related to time the deciduous molars functioned in the mouth. The main ions released from the glass-ionomer material are strontium, silica, alumina and fluorine while calcium content was increased. The fluorine content of enamel reaches 1.2\% (12,000ppms) as early as two weeks in vitro and remains constant even after 48 months in vivo. In dentin the fluorine content increase in relation to time and after 48 months in vivo it reached $1.2 \%$ $(12,000 \mathrm{ppms})$. Strontium, silica and alumina are transferred to enamel and dentin and their concentrations are related to time in vivo.

Ion migration from restorative materials into enamel and dentin has been determined in vitro in permanent and deciduous enamel and dentin [15]. The greatest extent of migration was observed when conventional glass-ionomer material was used and least migration was observed for the fluoride-releasing composite. Estimation of trace elements in sound enamel of deciduous teeth showed that fluorine, potassium and silica were significant higher when compared to carious enamel. In permanent sound enamel fluorine, strontium, potassium, alumina and iron were significantly higher in comparison to carious enamel [18]. In an in vivo research on the effect of glass-ionomer material on carious dentin in permanent molars extracted after 1-3 months, it was shown that strontium and fluorine from the restoration material penetrated deep into the underlying demineralized dentin. The pattern of penetration was consistent with a remineralization process [2].

The results of this study showed that fluorine, strontium and alumina migrate from glass-ionomer restorative material into enamel and dentin, and the concentration is related to the time the restoration function in vivo up to 4 years.

Fluorine concentration in enamel reached a high peak of 12,000 ppm as early as two weeks in vitro and remained constant through the 4 years in vivo. In dentin the increase of fluorine content was related to time and reached 12,000 ppm after 4 years.

Strontium is quantitatively incorporated into hydroxyapatite where its substitution for calcium provokes a linear increase in the lattice constant [19]. Strontium is added to glass-ionomer materials to confer radiopacity, but studies indicate that it may have a caries inhibitory role on both Streptccocuso mutans and Actinomyces viscosus, and its' effect may be more significant than that of fluorine [20], although Dabsie and associates [21] claimed that strontium alone showed no antibacterial effect when used as solution of strontium chloride hexahydrate directly on known bacterial inoculation for a short time of 5 minutes. Addition of strontium to fluoride in vitro resulted in an increased protection of enamel against fermentation attack by Streptococcus sobrinus [22] and in a significant enhancement of enamel remineralization in vitro, suggesting an interaction between fluoride and strontium when used in conjunction [23]. Exposure of enamel to strontium chloride solution in vitro reduced the loss of calcium from intact teeth or carious teeth by half when exposed to lactic acid, with no effect on enamel hardness [24]. In this study the concentration of strontium reached a peak of 5.2-5.4\% in enamel and dentin.

Topical alumina may possess cariostatic properties. Alumina may be incorporated in both sound and demineralized enamel and increases the resistance of hard tissue to acidic challenge [25]. The concentration of alumina in enamel and dentin in this study was $3.5-3.7 \%$ after 4 years in vivo.

Previous studies showed that solutions of strontium and fluorine or alumina and fluorine enhanced remineralization and inhibited demineralization as effective as fluorine solutions and significantly increased resistance to acidic attack [25].

We can postulate that the effect of fluorine together with strontium and alumina results in better protection of tooth structure to demineralization and bacterial attack and enhancement of remineralization beneath the restorative material. The use of conventional glass-ionomer restorative materials results in better protection of teeth in vivo against secondary carries and enhances remineralization. The migration of calcium from tooth components into glass ionomer may explain the additional mineralization of the restorative material as observed by van Duinen and associates [26].

The author don't have any non-financial competing interest relating to political, religious, ideological, educational, rational, commercial, etc., in relation to the manuscript.

\section{Competing interests}

The author declares that he has no competing interests.

\section{Publication history}

EIC: Thimios A. Mitsiadis, University of Zurich, Switzerland. Editors: Prasanna Neelakantan, Saveetha University, India. Petros Papagerakis, University of Michigan, USA.

Received: 18-Oct-2013 Revised: 17-Dec-2013

Accepted: 30-Dec-2013 Published: 06-Jan-2014 


\section{References}

1. Ten Cate JM and van Duinen RN. Hypermineralization of dentinal lesions adjacent to glass-ionomer cement restorations. J Dent Res. 1995; 74:1266-71. | Article | PubMed

2. Ngo HC, Mount G, Mc Intyre J, Tuisuva J and Von Doussa RJ. Chemical exchange between glass-ionomer restorations and residual carious dentine in permanent molars: an in vivo study. J Dent. 2006; 34:608-13. | Article | PubMed

3. Bezerra AC, Novaes RC, Faber J, Frencken JE and Leal SC. Ion concentration adjacent to glass-ionomer restorations in primary molars. Dent Mater. 2012; 28:e259-63. | Article | PubMed

4. Lodrop $\mathrm{H}$. The low rate of dental decay in Bonn/Rhein and the conclusions that can be drawn from it. Norske Tandlaegeforen Tid. 1953; 63:35-50.

5. Barmes DE. Caries etiology in Sepik villages--trace element, micronutrient and macronutrient content of soil and food. Caries Res. 1969; 3:44-59. | Article | PubMed

6. Curzon ME, Adkins BL, Bibby BG and Losee FL. Combined effect of trace elements and fluorine on caries. J Dent Res. 1970; 49:526-8. | Article | PubMed

7. Curzon ME and Losee FL. Strontium content of enamel and dental caries. Caries Res. 1977; 11:321-6. | Article | PubMed

8. Athanassouli TM, Papastathopoulos DS and Apostolopoulos AX. Dental caries and strontium concentration in drinking water and surface enamel. J Dent Res. 1983; 62:989-91. | Article | PubMed

9. Gedalia I, Anaise J and Laufer E. Effect of prenatal, preeruptive, and posteruptive strontium administration on dental caries in hamster molars. J Dent Res. 1975; 54:1240. | Article | PubMed

10. Niedzielska K, Struzak-Wysokinska M and Wujec Z. [Analysis of correlations between the content of various elements in hard tissues of milk teeth with and without caries]. Czas Stomatol. 1990; 43:316-22. PubMed

11. Riyat $M$ and Sharma DC. Analysis of 35 inorganic elements in teeth in relation to caries formation. Biol Trace Elem Res. 2009; 129:126-9. | Article I PubMed

12. Riyat $M$ and Sharma DC. Significance of trace element profile of blood of persons with multiple caries versus sound teeth. Biol Trace Elem Res. 2010; 134:174-9. | Article | PubMed

13. Shigemi T, Tanaka T, Hayashida $Y$ and Maki K. Study of salivary strontium and silver concentrations in primary school children related to dental caries. Biol Trace Elem Res. 2008; 123:80-90. | Article | PubMed

14. Sidhu SK and Schmalz G. The biocompatibility of glass-ionomer cement materials. A status report for the American Journal of Dentistry. Am J Dent. 2001; 14:387-96. | Article | PubMed

15. Gjorgievska E, Nicholson JW and Grcev AT. Ion migration from fluoridereleasing dental restorative materials into dental hard tissues. J Mater Sci Mater Med. 2012; 23:1811-21. | Article I PubMed

16. Duque C, Negrini Tde C, Hebling J and Spolidorio DM. Inhibitory activity of glass-ionomer cements on cariogenic bacteria. Oper Dent. 2005; 30:636-40. | PubMed

17. da Silva RC, Zuanon AC, Spolidorio DM and Campos JA. Antibacterial activity of four glass ionomer cements used in atraumatic restorative treatment. J Mater Sci Mater Med. 2007; 18:1859-62. | Article | PubMed

18. Shashikiran ND, Subba Reddy VV and Hiremath MC. Estimation of trace elements in sound and carious enamel of primary and permanent teeth by atomic absorption spectrophotometry: an in vitro study. Indian J Dent Res. 2007; 18:157-62. | Article | PubMed

19. Bigi A, Boanini E, Capuccini C and Gazzano M. Strontium-substitute hydroxyapatite nanocrystals. Inorganica Chimica Acta. 2007; 360:100916. | Article

20. Guida A, Towler MR, Wall JG, Hill RG and Eramo S. Preliminary work on the antibacterial effect of strontium in glass ionomer cements. Journal of Material Science Letters. 2003; 22:1401-3. | Article

21. Dabsie F, Gregoire G, Sixou M and Sharrock P. Does strontium play a role in the cariostatic activity of glass ionomer? Strontium diffusion and antibacterial activity. J Dent. 2009; 37:554-9. | Article | PubMed

22. Luoma H, Nykanen I, Seppa L, Alakuijala P, Spets-Happonen $S$ and Raisanen J. Protection by F, I, Sr, and combinations against fermentation attack by Streptococcus sobrinus artificial plaque on bovine enamel. Caries Res. 1989; 23:5-13. | Article | PubMed

23. Thuy TT, Nakagaki H, Kato K, Hung PA, Inukai J, Tsuboi S, Hirose MN, Igarashi $S$ and Robinson C. Effect of strontium in combination with fluoride on enamel remineralization in vitro. Arch Oral Biol. 2008; 53:1017-22. | Article | PubMed

24. Riyat $M$ and Sharma DC. An experimental study of the effect of strontium pre-treatment on calcium release from carious and noncarious teeth. Biol Trace Elem Res. 2010; 133:251-4. | Article | PubMed

25. Koletsi-Kounari H, Mamai-Homata E and Diamanti I. An in vitro study of the effect of aluminum and the combined effect of strontium, aluminum, and fluoride elements on early enamel carious lesions. Biol Trace Elem Res. 2012; 147:418-27. | Article | PubMed

26. Van Duinen RN, Davidson CL, De Gee AJ and Feilzer AJ. In situ transformation of glass-ionomer into an enamel-like material. $\mathrm{Am} \mathrm{J}$ Dent. 2004; 17:223-7. I PubMed

\section{Citation:}

Zilberman U. Ion exchanges between glass-ionomer restorative material and primary teeth components-an in vivo study. Oral Biol Dent. 2014; $2: 1$.

http://dx.doi.org/10.7243/2053-5775-2-1 